\title{
Small airway dysfunction and bronchial asthma control : the state of the art
}

\author{
Marcello Cottini ${ }^{1}$, Carlo Lombardi ${ }^{*}$ and Claudio Micheletto ${ }^{3}$
}

\begin{abstract}
According to national and international guidelines, achieving and maintaining asthma control is a major goal of disease management. In closely controlled clinical trials, good asthma control can be achieved, with the medical treatments currently available, in the majority of patients, but large population-based studies suggest that a significant proportion of patients in real-life setting experience suboptimal levels of asthma control and report lifestyle limitations with a considerable burden on quality of life. Poor treatment adherence and persistence, failure to use inhalers correctly, heterogeneity of asthma phenotypes and associated co-morbidities are the main contributing factors to poor disease control. Now, it is widely accepted that peripheral airway dysfunction, already present in patients with mild asthma, is a key contributor of worse control. The aim of this paper is to investigate the association between small-airways dysfunction and asthma symptoms/control. We therefore performed a PubMed search using keywords : small airways; asthma (limits applied: Humans, English language) and selected papers with a study population of asthmatic patients, reporting measurement of small-airways parameters and clinical symptoms/control.
\end{abstract}

Keywords: Small-airways disease, Bronchial asthma, Phenotypes, Asthma control

\section{Background}

Asthma is one of the most common chronic conditions in the world and the most common non-communicable disease among children [1]; according to the World Health Organization, the Global Burden of Disease Study and the Global Asthma Report 2014 [2-4], asthma affects an estimated 334 million people worldwide. The prevalence of asthma has been reported to range from 1 to $18 \%$ of the population in different countries [4]. Most people affected are in low- and middle-income countries, and the prevalence of asthma is estimated to be increasing fastest in those countries [4]. In Europe alone, asthma affects 30 million people $[5,6]$ and is associated with a significant socioeconomic burden $[7,8]$. The Global Burden of Disease Study estimated that asthma was the 14th most important disorder in terms of global years lived with disability [3].

The main goal of current asthma treatment guidelines is to achieve clinical control, including control of

\footnotetext{
* Correspondence: carlo.lombardi@poliambulanza.it

${ }^{2}$ Departmental Unit of Allergology, Immunology \& Pulmonary Diseases,

Fondazione Poliambulanza, Via Bissolati, 57, Brescia 25124, Italy
}

Full list of author information is available at the end of the article symptoms (daytime symptoms, night-time awakenings and reliever inhaler use), maintenance of normal activity levels and to prevent exacerbations $[9,10]$.

Randomized controlled trials showed that asthma control is an achievable target [11], but the incidence of asthma control in "real-life" clinical practice is considerably lower and a substantial proportion of asthmatics remain not well-controlled [12-14]. Randomized controlled trials (RCT) are not representative of real-life, because recruitment often includes only patients with no (or negligible) co-morbid illnesses or concurrent medications, those with good inhaler technique and high adherence to study therapies [15]. Lifestyle characteristics, as cigarette smoking, typically result in patient exclusion. The level of asthma control is poor even in patients with mild asthma, regularly treated with inhaled steroids [16]. Poor asthma control is associated with increased risk of exacerbations, impaired quality of life, increased health-care utilization and reduced productivity [17-19]. History of asthma exacerbations, poor treatment adherence, failure to use inhalers correctly, heterogeneity of asthma phenotypes and associated comorbidities are 
the main contributing factors to poor disease control [20-24]. Recent studies suggest that persistent uncontrolled inflammation in the peripheral small airways can also contribute to clinical expression and worse control of asthma [25]. Historically, the small airways are defined as airways with an internal diameter of less than $2 \mathrm{~mm}$ that do not contain cartilage in their walls and extend from the 8th generation airways to the periphery of the lung, referring to the landmark study of Macklem and Mead [26]. It is well established that inflammation and remodeling in asthma involve the large airways, but it is now widely accepted that small airways are the major site of inflammation in asthma [27], with a chronic inflammatory infiltrate consisting of eosinophils, $\mathrm{T}$ lymphocytes, neutrophils, and macrophages; moreover transbronchial biopsy findings show small airways inflammation and remodeling in all severities of asthma [27-30]. The small airways are known as the "quiet zone" because they make only a small contribution to airway resistance under normal circumstances. Conventional physiological measurements are unable to sensitively evaluate this airway region [31, 32] and may become abnormal only once there is a significant burden of disease, but in recent years more specialized tests have been developed, which may better assess small-airways dysfunction. These tests are now moving from clinical research laboratories into routine clinical practice. Table 1 summarizes the techniques available for the assessment of small airways disease. No assessment method is universally and directly representative of peripheral airway function and the value and limitations of each test have been extensively reviewed [33-35].

Evidence is accumulating to support a high prevalence of impaired small airway function in patients with asthma. Anderson and Colleagues [36] studied with impulse oscillometry (IOS) the prevalence of small airways dysfunction (SAD) in 368 patients with community managed persistent asthma who were receiving treatment as defined by British Thoracic Society (BTS). An abnormal value for peripheral airways resistance (defined as R5-R20 higher than $0.03 \mathrm{kPa} / \mathrm{l}^{-1}$ ) was noted in $65 \%$ of patients on step two BTS treatment, $64 \%$ of patients on step three treatment, and $70 \%$ of patients on BTS step four treatment. Perez and colleagues [37] studied 441 patients with moderate-to-severe asthma with normal FEV1 and FEV1/FVC, treated with an association of ICSs and LABAs. The prevalence of SAD was estimated by both spirometry and plethysmography and defined by the presence of the following parameters: (1) the difference between SVC and FVC to detect expiratory air trapping; (2) FEF $25-75 \%$, and FEF $50 \%$, to detect distal airflow limitation; (3) functional residual capacity, RV, and RV/TLC as marker of air trapping/lung hyperinflation, a phenomenon closely associated with small airways dysfunction (premature small airways closure or near closure: the small airways begin to collapse at a higher volume before expiration is complete). SAD was found in more than half of the patients indicating that the routinely used lung function tests can underestimate dysfunctions occurring in the small airways. Recent studies suggest that abnormalities in the small airways can contribute to the clinical expression of asthma [34, 35, 38] and a systematic review showed that SAD is associated with worse asthma control, a higher number of exacerbations, the presence of nocturnal asthma, more severe bronchial hyperresponsiveness (BHR) and exerciseinduced asthma [25]. Air trapping/lung hyperinflation are characteristic features of the severe asthma population $[29,85,88]$ indicating an additional potential severe asthma phenotype [29].

\section{Small airways dysfunction and asthma symptoms}

Several studies have linked small airway function to asthma symptoms. Recently, Schiphof-Godart et al. selected patient with SAD, based on FEF $50 \%$, and R5-R20 values from spirometry and IOS respectively [39].

Table 1 Techniques available for the assessment of small airways disease in comparison to large airway

\begin{tabular}{|c|c|c|}
\hline Method & Small airway function & Large airway function \\
\hline Spirometry & FEF25-75\%, FVC, FVC/SVC & FEV1, FEV1/FVC \\
\hline Impulse oscillometry (IOS) & R5-R20, X5, AX, Fres & $\mathrm{R} 20$ \\
\hline $\begin{array}{l}\text { Single Breath Nitrogen Washout (SBNW) or Multiple Breath } \\
\text { Nitrogen Washout (MBNW) test }\end{array}$ & Slope phase III, CV, CC, Sacin, Scond & \\
\hline Body plethysmography & $\mathrm{RV}, \mathrm{RV} / \mathrm{TLC}$ & \\
\hline $\begin{array}{l}\text { High Resolution Computerized Tomography (HRCT)Nuclear medicine } \\
\text { (Scintigrapy,SPECT,PET)3He-MRI }\end{array}$ & $\begin{array}{l}\text { Air trapping, airway wall thicknessRegional ventilation } \\
\text { defectsNonventilated lung volume }\end{array}$ & Airway wall thickness \\
\hline Bronchoscopy & Transbronchial biopsy, BAL & Endobronchial biopsy \\
\hline Sputum induction & Late phase sputum & Early phase sputum \\
\hline Exhaled nitrix oxide (eNO) & Alveolar eNO & Bronchial eNO \\
\hline CT \& computational fluid dynamics & Changes in airway volume and resistence & \\
\hline
\end{tabular}


Patients with SAD reported to wheeze easily, were unable to breathe in deeply, mentioned more symptoms related to BHR, experienced more pronounced exerciseinduced symptoms and more frequently had allergic respiratory symptoms after exposure to allergens. According to asthma treatment guidelines $[9,10]$, the presence of night-time awakenings and activity limitation due to exercise-related symptoms is a key factor for worse asthma control. A history of EIB and exerciserelated respiratory symptoms occur more commonly in patients with not well and very poorly controlled asthma. Small airways involvement has been implicated in exercise-induced asthma (EIA) and in the severity of exercise-induced bronchoconstriction (EIB). Kaminsky et al. reported that the small airways of patients with EIA are responsive to cool, dry air, which suggests that they play an important role in asthma in this patient population [40]. The Authors also reported that baseline peripheral airway resistance correlated significantly with the degree of EIB in asthmatic patients. Decramer et al. showed that peripheral resistance, as measured with the forced oscillation technique, increases after a hyperventilation test with cold, dry air [41]. This alteration is compatible with a more generalized constriction of the peripheral as well as central airways. In asthmatic children, $\mathrm{FEF}_{25-75} \%$, a parameter of small airways function, decrease in response to exercise without changes in FEV1, mainly in patients with mild asthma [42]. Testing mild asthmatic patients for airway hyperresponsiveness with indirect stimuli, Aronsson et al. [43] showed that those positive to mannitol had a significant increased baseline value of IOS parameters such as $\Delta R 5-R 20$ and reactance area (AX). Lee et al. evaluate the characteristics of airway obstruction in young asthmatics after an exercise bronchial provocation test using IOS : more severe exercise-induced bronchoconstriction is associated with a higher increase in peripheral airways resistance (R5-R20) but not with an increase in large-airways resistance (R20) [44]. Two studies investigated the phase III slope of the single-breath washout test before and after a cold, dry air hyperventilation test and demonstrated that an increase in the helium and sulfur hexafluoride phase III slopes were associated with the degree of EIB in the asthma patients [45, 46]. Chinellato et al. assessed the correlation between alveolar production $\left(\mathrm{C}_{\mathrm{alv}} \mathrm{NO}\right)$ and bronchial flux $(\mathrm{J}(\mathrm{NO})$ of nitric oxide and EIB in asthmatic children [47]. A significant correlation was observed between severity of EIB and inflammation of the central and peripheral airways. Linkosalo et al. showed that in atopic children and adolescents increased alveolar NO concentration correlated with the degree of obstruction in smaller airways induced by exercise challenge [48]. Taken together, these findings support the view that inflammation and dysfunction in the peripheral airways are crucial for more pronounced exercise-induced symptoms in asthma.

Nocturnal symptoms and worsening of lung function at night are common among patients with asthma and are associated with poor asthma control. Several studies investigate the association between SAD and nocturnal asthma. Kraft and Colleagues have reported that patients with nocturnal asthma demonstrate increase in peripheral airways resistance and greater inflammatory involvement of the small airways [49, 50]. Patients with nocturnal asthma exhibited significantly greater numbers of eosinophils in the distal airways compared to the proximal airway tree in biopsies undertaken during the night and in bronchoalveolar lavage fluid $[50,51]$. Lehtimaki et al. evaluate patients with newly-diagnosed steroid-naive asthma, assessing alveolar NO concentration and bronchial NO flux in 40 asthmatics and 40 healthy controls [52]. Patients with nocturnal symptoms had a higher alveolar NO concentration $(1.7 \pm 0.3$ parts per billion (ppb)) than patients without nocturnal symptoms $(0.8 \pm 0.3 \mathrm{ppb}, p=0.012)$ or healthy controls (1.0 \pm $0.1 \mathrm{ppb}, p=0.032$ ), suggesting that even in patients with mild asthma, nocturnal symptoms are associated with small-airways inflammation. Taken together, these studies support the concept that SAD may contribute to the increased night-time symptoms in patients with nocturnal asthma.

Obesity has been linked with asthma symptoms, need for asthma treatment and reduced lung function [53]. Recently, Al-Alwan et al. evaluated lung function by conventional clinical tests and by impulse oscillometry in female late-onset, non-allergic patients with asthma and control subjects before, and 12 months after, bariatric surgery [54]. Weight loss decompresses the lung in both obese control subjects and patients with asthma, but there was a significantly different response to weight loss in patients with asthma compared with control subjects, and this result lead the Authors to the novel hypothesis that obese patients with asthma are distinguished from obese control subjects by having excessive collapsibility of the lung periphery, perhaps as a consequence of reduced distal airway wall stiffness.

\section{Small airways dysfunction and asthma control}

Takeda et al. performed IOS, spirometry, assessment of health status (Asthma Quality of Life Questionnaire and St. George's Respiratory Questionnaire), dyspnea (Baseline Dyspnea Index) and disease control (Asthma Control Questionnaire) in 65 patients with stable asthma [55]. Small airway function as evaluated by peripheral airway IOS indices, correlated better with clinical symptoms and asthma control than spirometry; furthermore, greater small-airways reactance was associated with loss of asthma control. Pisi et al. investigated the presence of 
SAD based on increased peripheral airway IOS indices in 33 adult asthmatic patients with normal FEV1 values [56]. Small airway dysfunction, as assessed by IOS and spirometry, was associated with poor disease control, assessed by the Asthma Control Test. Recently, Manoharan and Colleagues valuated adult asthmatics with a preserved FEV1 (>80\% predicted) [57]. Spirometry and IOS measurements were linked to prescription data. Persistent small airway dysfunction, defined by FEF $25-75 \%$, and R5-R20, was associated with a significantly increased likelihood of having worse long-term asthma control. The risk of having poorer control was greater when measurements of FEF $25-75 \%$, and R5-R20 were combined. These studies support the concept that in adult asthmatics who have a preserved FEV1, a persistent small airway dysfunction is associated with poorer control, perhaps suggesting the presence of a defined "small airway asthma phenotype" characterized by individuals with healthy values for conventional measures of pulmonary function but poor control of disease and a disproportionate amount of small airway dysfunction [58]. This situation is very common in childhood, where FEV1 is generally normal, even in severe persistent asthma [59]. Several studies in children have linked uncontrolled asthma to small airway function. Rao et al. used The Children's Hospital Boston Pulmonary Function Test database to compare matched groups of children with asthma [60]. Subjects with a low FEF $25-75 \%$, had a worse control of asthma and more exacerbations . Shi et al. assessed 57 children with controlled asthma and 44 children with uncontrolled asthma with spirometry and IOS: they found that small airway IOS measurements (R5-R20 and reactance area values) could discriminate between patients with controlled and uncontrolled asthma, with a high sensitivity and specificity of 84 and $86 \%$ [61]. The sensitivities of spirometry outcomes for assessing uncontrolled asthma were low, especially for FEV1 and bronchodilator responsiveness. In a prospective follow-up study of the same group [62], children with controlled asthma who have increased peripheral airway IOS indices (reactance area $>0.70 \mathrm{kPa} / \mathrm{L}$ and $\mathrm{R} 5-\mathrm{R} 20>0 \cdot 10 \mathrm{kPa} / \mathrm{l}^{-1}$ ) are at risk of losing asthma control.

Many studies assessed ventilation heterogeneity: increasing unevenness of ventilation between different lung regions is a sensitive marker of abnormal smallairway function and can be measured noninvasively by using the single-breath washout (increase in the phase III slope, dN2) or multiple-breath washout techniques (MBNW) [61-66]. MBNW is able to distinguish between ventilation heterogeneity generated in the conductive lung zone (Scond) and ventilation heterogeneity generated in the acinar lung zone (Sacin) [32]. Bourdin et al. demonstrated that patients with more alveolar heterogeneity, as determined with the phase III slope of the single-breath nitrogen test (SBNT), have worse asthma control [67]. Singer et al. assessed ventilation heterogeneity with an easy tidal breath single-breath washout (SBW) technique in school-aged children with mild asthma and normal FEV1 and healthy age-matched control subjects [68]. Abnormal acinar ventilation heterogeneity in one-third of the children suggests that small airways disease may be present despite mild asthma symptoms and normal spirometry. Farah et al. demonstrated in a cross-sectional analysis of a large cohort that subjects with poorly controlled asthma had worse ventilation heterogeneity compared with wellcontrolled subjects [69]. Furthermore, during a period of ICS treatment, the change in ventilation heterogeneity predicted the change in asthma symptom control independently of all other measured physiologic variables. The same group demonstrated that ventilation heterogeneity predicts symptomatic improvement to ICS dose up-titration and loss of symptom control during downtitration [70]. Recently Thompson and Colleagues, using the multiple-breath washout techniques (MBNW), demonstrated that in patients with poorly controlled asthma a functional abnormality in the acinar lung zone showed a direct correlation with airflow obstruction and treatment requirement [71].

With regard to peripheral inflammation, Van Vyve et al. investigated inflammation in bronchoalveolar lavage (BAL) fluid [72]. Uncontrolled asthma was associated with a higher eosinophil percentage in BAL fluid, suggesting involvement of the small airways.

Several studies in children and adults have demonstrated that higher alveolar nitric oxide concentrations are associated with the presence of worse asthma control [72-76]. Corcuera-Elosegui et al. recently assessed 162 children with spirometry, exhaled $\mathrm{NO}$ at multiple flow and asthma control questionnaire (ACQ): FEV1/FVC decreased significantly and morbidity was significantly higher in asthmatics with elevated alveolar nitric oxide concentrations [77]. Puckett et al. measured baseline spirometry, bronchodilator response, eNO at multiple flows $(50,100$, and $200 \mathrm{ml} / \mathrm{s})$, asthma control and morbidity in 200 children with asthma and 21 nonasthmatic, non-atopic controls and divided children into 4 groups based on the concentration of alveolar and bronchial NO: only categories with increase alveolar nitric oxide concentrations were related to poor asthma control and morbidity independent of baseline spirometry, bronchodilator response, atopic status, or use of inhaled corticosteroids. Scichilone and Colleagues utilized the index of alveolar nitric oxide as a marker of small airways inflammation in patients with mild asthma and established that the level of disease control, assessed using the asthma control test (ACT), was directly 
associated with peripheral airways inflammation: in uncontrolled asthmatic patients compared to controlled patients, worsening alveolar nitric oxide concentrations correlated with worsening ACT scores [79].

\section{Small airway disfunction and asthma exacerbations}

The focus of clinical practice guidelines for asthma $[9,10]$ has shifted to include not only the conventional assessment of symptoms, reliever use, and activity limitation but also assessment of the patient's future risk of adverse outcomes, such as exacerbations, future poor asthma control, accelerated decline in lung function, and adverse effects of medications. Uncontrolled asthma symptoms substantially increase the risk of exacerbations [80, 81], but data from the European Network for Understanding Mechanisms of Severe Asthma (ENFUMOSA) found that patients with a history of near-fatal asthma in the past 5 years could not be reliably distinguished from those with mild to moderate asthma in stable conditions using common measures of asthma severity and control [82]. Identification of patient's risk profile is important to enable recognition of patients at high risk. Risk factors for exacerbations include: history of severe exacerbation, uncontrolled asthma symptoms, having $\geq 1$ exacerbation in last 12 months, low FEV1, incorrect inhaler technique and/or poor adherence, smoking, obesity, pregnancy and blood eosinophilia [83].

Accumulating evidence suggests that a higher degree of peripheral airway dysfunction is associated with more frequent asthma exacerbations. Rao et al. showed that asthmatic children with a low FEF $25-75 \%$, had nearly 3 times the odds (OR 2.8, $p<0.01$ ) of systemic corticosteroid use and 6 times the odds of asthma exacerbations (OR 6.3, $p>0.01$ ) compared with those who had normal spirometry [60]. The Authors conclude that a low FEF $25-75 \%$, in the setting of a normal FEV1 is associated with increased asthma severity, systemic steroid use and asthma exacerbations in children. Pisi et al. investigated the presence of SAD by IOS in asthmatic patients with normal FEV1 values [54]. Increased R5-R20 values were significantly higher in patients with asthma exacerbations, when compared with patients without asthma exacerbations. Two studies investigated the relationship between ventilation heterogeneity and asthma exacerbations; Bourdin et al. [67] showed that frequent $(>2 / y)$ exacerbators have a higher degree of ventilation inequalities (a sensitive marker of abnormal small-airway function), as determined with SBNT phase III slope, than infrequent exacerbators $(<2 / y)$, whereas FEV1 percent predicted values were comparable between these two groups. Veen and Colleagues observed that difficult-totreat asthmatics with frequent disease exacerbations exhibited enhanced airway closure (assessed as closing volume and closing capacity) compared to equally severe asthmatics without recurrent exacerbations [84].

In asthmatic children, Mahut et al. recorded forced expiratory flows and plethysmographic lung volumes (TLC, FRC, RV) before and after bronchodilation : air trapping (higher RV and RV/TLC) was associated with occurrence of a severe exacerbation during the last 3 months, suggesting a small airway disease that is not evidenced by forced expiratory flows [85]. Imaging with $\mathrm{CT}$ also allows assessment of small airways in obstructive pulmonary diseases [86]. High-resolution CT allows direct assessment of large and medium airways (diameter $>2-2.5 \mathrm{~mm}$ ), and indirect assessment of small airways. Areas of mosaic lung attenuation on inspiratory $\mathrm{CT}$ and air trapping on expiratory CT have been evaluated as markers of small airways disease in both asthma and COPD [87]. Busacker et al. assess with CT scanning a subset of Severe Asthma Research Program subjects; asthmatic patients with air trapping were significantly more likely to have a history of asthma-related hospitalizations, ICU visits, and/or mechanical ventilation [88]. Duration of asthma, history of pneumonia, high levels of airway neutrophils, airflow obstruction (FEV(1)/FVC) and atopy were identified as independent risk factors associated with the air-trapping phenotype. Furthermore, two studies in adults and children showed that patients with increased alveolar NO levels more frequently had visits to the emergency department, severe attacks, and hospitalizations [77, 78].

As a predictor of future risk, increased BHR appears to be, in children and adults with asthma, a significant and independent risk factor for loss of control, asthma exacerbations and development of irreversible loss of lung function [89]. Several studies have demonstrated a strong correlation between small airways dysfunction and BHR. In a landmark study, Wagner et al., using a fiberoptic bronchoscope wedged into a subsegmental bronchus, demonstrated that greater peripheral airways resistance was associated with more BHR to methacholine [90]. BHR can be present in subjects without any respiratory symptoms. In 185 subjects, Segal et al. showed that distal airway heterogeneity, as reflected by higher R5-R20 and lower X5 values, was associated with methacholine-induced symptoms despite absence of change in FEV1 [91]. Boudewijn et al. investigated small airway function assessed by spirometry and impulse oscillometry, as well as Borg dyspnea scores at baseline and during a methacholine provocation test in 15 subjects with asymptomatic BHR, 15 asthma patients, and 15 healthy controls [92]. Small airway function (R5-R20 and X5 ) was comparable between subjects with asymptomatic BHR and healthy controls, whereas asthma patients showed small airway dysfunction as reflected by higher R5-R20 and lower X5 values. Beretta et al. used 
the IOS to gain information concerning the distribution of hyper-reactivity along the bronchial tree during methacholine challenge test [93]. For PD20 $<200 \mu \mathrm{g}$, a remarkable frequency dependence was observed, with increase in R5, no change in R20, and decrease in X5, suggesting hyper-responsiveness of the distal airways paralleled by a change in visco-elastic properties of lung parenchyma. Several studies have suggested that smallairways dysfunction is associated with more severe BHR. Telenga et al. analyzed data from patients with mild-tomoderate asthma: all patients were hyperresponsive to histamine (PD20 $<9 \mathrm{mcg}$ ) [94]. Small airways obstruction was defined as a MEF 50 of less than or the same as the lower limit of normal.The Authors found that small airways obstruction is associated with the severity of BHR in asthma, independently of FEV1. Downie et al. analyzed, in 40 subjects with asthma, airway inflammation by exhaled nitric oxide, ventilation heterogeneity by multiple breath nitrogen washout and BHR by methacholine challenge: baseline ventilation heterogeneity was a strong predictor of BHR, independent of airway inflammation in subjects with asthma [95]. While a PD20 value is measurable in the vast majority of asthma patients during the methacholine challenge, a significant $\triangle \mathrm{FVC} \%$ value is not always detectable in asthmatic patients. A fall in FVC suggests small airway closure and gas trapping: excessive bronchoconstriction during BHR testing is considered to be a very important pathophysiological determinant in severe acute asthma exacerbations $[96,97]$. Furthermore, $\triangle \mathrm{FVC} \%$ correlated to asthma treatment in adult patients and to the presence of symptoms in children with asthma [98, 99]. Recently, Alfieri et al. provide the first evidence that in asthmatic patients excessive bronchoconstriction expressed by $\triangle \mathrm{FVC} \%$ is strictly associated to small airway dysfunction, as assessed by IOS [100]. As compared to patients with $\mathrm{R} 5-\mathrm{R} 20 \leq 0.030 \mathrm{kPa} \mathrm{s} \mathrm{l}^{-1}$, patients with $\mathrm{R} 5-\mathrm{R} 20>0.030$ $\mathrm{kPa} \mathrm{s} \mathrm{^{-1 }}$ had a high likelihood to be associated to a $\triangle \mathrm{FVC} \%$ greater than $14.5 \%$ during a methacholineinduced bronchoconstriction.

\section{Effect of asthma treatment on small-airways function and control of disease}

Taken together, these findings support the view that distal lung is a very important target in any therapeutic strategy for effective treatment. The inability to reach and treat the peripheral airways may contribute to the lack of efficacy of inhaled treatments. Several studies have assessed the ability of both inhaled small particle aerosols and oral treatments to target the distal airways and improve physiological indices and levels of asthma control. Anti-inflammatory treatment with inhaled corticosteroids(iCSs), with or without long-acting $\beta 2$ adrenoceptor agonists (LABA), is the cornerstone of asthma management $[9,10]$. The recent development of inhaled extrafine formulations allows a more uniform distribution of the inhaled treatment throughout the respiratory tree to include the peripheral airways [101]. Extrafine formulations, with an mass median aerodynamic diameter (MMAD) of approximately 1 to $1.5 \mu \mathrm{m}$, have a higher lung deposition (50 to $60 \%$ ) than coarse particle ICSs with an MMAD of 3 to $4 \mu \mathrm{m}$ (10 to $20 \%)$ and then penetrate more deeply into the peripheral airways than drugs delivered via traditional inhalers [102-104].

Different biomarkers of peripheral airways are improved by extrafine inhaled corticosteroids (beclomethasone, ciclesonide, flunisolide) in comparison with equivalent non-extrafine inhaled formulations: ventilation heterogeneity [105], peripheral airways resistance [36, 106], BHR [107], alveolar nitric oxide concentrations [108], late phase sputum [109], and peripheral airway air trapping [110]. These improvements are associated with better asthma control [111-113], higher health-related quality of life [114-116] and better cost-effectiveness [116], along with reduced systemic exposure to inhaled corticosteroids [117], because comparable clinical effects can be obtained with a lower amount of delivered compound and with fewer unwanted effects .

Recently, the HFA-propelled extra-fine fixed combination formulation of beclomethasone dipropionate/ formoterol (BDP/F) 100/6 $\mu \mathrm{g}$ has been developed $[101,118]$ and represents the only extrafine combination in both the pMDI and DPI formulations developed thus far [118].

Because of the small particle size of BDP/F, the two active drugs are delivered to both central and peripheral airways, resulting in a uniform treatment of inflammation and bronchoconstriction [119, 120]. In asthmatic patients BDP/F HFA significantly improved functional parameters reflecting small airway obstruction in comparison with equivalent non-extrafine inhaled formulations : forced vital capacity percent of predicted (\%FVC, a simple indicator of small airways involvement) [121, 122], ventilation heterogeneity [123-125], peripheral airways resistance [126], local airway resistance obtained from computational fluid dynamics [127], BHR [124], and alveolar nitric oxide concentrations [127].

Huchon et al. showed that after 24 weeks of treatment extrafine BDP/F delivered by an HFA pMDI $(400 / 24 \mu \mathrm{g})$ was superior in improving asthma control to the combination of the same drugs formulated as larger nonextrafine agents at equipotent doses $(1000 \mu \mathrm{g} \mathrm{BDP} \mathrm{+}$ $24 \mu \mathrm{g}$ F) [128].

This is in line with results of several real-life studies [122, 129-132] showing that the use of extrafine-particle HFA-beclomethasone/formoterol was associated with a higher percentage of patients with well controlled 
asthma based on their Asthma Control Test and ACQ scores than the use of non-extrafine combination treatment. These improvements are associated with better health-related quality of life $[122,130,131]$ and costeffectiveness [132, 133]. Additionally, in most studies the Authors observed that the mean daily dose of iCSs was much higher for the large particle aerosols compared to the small particle aerosols of BDP/Form. Brusselle and Colleagues [134] have also shown that the benefits of small particle HFA-solution BDP/F aerosols on improving levels of disease control in non-smoking patients with asthma are also observed in asthmatic patients who currently smoke, reflecting real-life clinical practice, as often smoking asthmatic patients are excluded from randomized controlled clinical trials [134, 135].

Taken together, these studies show that extrafineparticle pressurized metered-dose inhalers might have additional clinical benefits in the treatment of asthma compared with coarse-particle treatment. Whether the clinical superiority in terms of control can be related to increased impact on distal lung abnormalities has not been demonstrated by an appropriately designed clinical study.

Montelukast is a systematically administered leukotriene receptor antagonist that reaches the small and large airways [136]. Leukotriene receptors are differently expressed in fibroblasts from peripheral compared to central airways [137], which may explain a suggested cysteinyl-leukotriene driven remodeling mainly in the peripheral airways and possibly resulting in a predominant effect of montelukast on the small airways. Several studies showed that biomarkers of peripheral airways are improved by montelukast: peripheral airways resistance [138, 139], air trapping [140-142], and alveolar nitric oxide $[138,144]$. There is suggestive evidence that a improvement in distal dysfunction/inflammation after treatment with montelukast is associated with better asthma control and asthma-related Quality of Life in adults and children [138, 141-143].

Systemic parenteral treatment with omalizumab (an anti-immunoglobulin IgE monoclonal antibody) is used in selected patients with severe allergic asthma on treatment step 5 of asthma guidelines $[9,10]$. In a prospective, time-series, single-arm observational study [145], 31 adult patients with severe refractory asthma despite the use of multiple controller medications, including highdose iCSs $(1432 \pm 581 \mu \mathrm{g} / \mathrm{d}$ of fluticasone propionate equivalent), were enrolled. Alveolar nitric oxide $\left(\mathrm{C}_{\text {alv }} \mathrm{NO}\right)$ levels and airway-wall thickness as assessed by computed tomography significantly decreased at 48 weeks. Conversely, Pasha et al. did not find an association between the placebo and treatment groups in overall $\mathrm{C}_{\text {alv }} \mathrm{NO}$ levels or in the changes of $\mathrm{C}_{\mathbf{a l v}} \mathrm{NO}$ with time (may be for the initial low $\mathrm{C}_{\text {alv }} \mathrm{NO}$ levels in this asthmatic population) [146].

\section{Conclusions}

Poor treatment compliance, failure to use inhalers correctly, heterogeneity of asthma phenotypes and associated comorbidities are the main contributing factors to poor disease control [20-24], but there is now a considerable amount of evidence supporting the concept that a higher level of small airway disease is associated with increased asthma symptoms, worse asthma control, more severe bronchial hyper-responsiveness, and an increased number of exacerbations [25]. Small-airways dysfunction is not only a feature of severe asthma : distal inflammation and remodeling are present in patients with all severities of disease [27-30]. Evidence is accumulating to support a distinct, "small aiways", clinical phenotype for patients with uncontrolled asthma who have impaired small airway function and conventional measures of pulmonary function in the normal range [58]. There is also suggestive evidence that, in some "clinical" asthma phenotypes, the small airways are more affected, including nocturnal asthma, severe steroid-dependent or difficultto-treat asthma, asthma complicated by smoking, elderly asthmatic patients and those with fixed airflow obstruction, and asthmatic children [147, 148]. Taken together, these findings support the view that distal lung is a very important target in any therapeutic strategy for effective treatment. The randomized clinical trials reported to date show that the extrafine and nonextrafine ICS formulations have similar efficacy in terms of primary endpoints; however the availability of small-particle aerosols enables a higher drug deposition into the peripheral lung [102-104] and potentially provides additional clinical benefits compared with large-particle treatment [147]. In several studies a better small-airways response to treatment with montelukast [142-144] or extrafine-particle ICSs [111-113] and ICS/LABA combination [128-132] is accompanied by better asthma control. Asthma is an inflammatory disease affecting the whole respiratory system, from central airways to lung parenchyma. Some patients have excellent control of disease with drugs that partially reach small airways, probably due to the heterogeneity of airway inflammation/dysfunction , but post hoc analysis of studies with non-extra-fine ICS/LABA combination to evaluate possible effects on small airways dysfunction are needed.

In addition to real-life studies, head to head (extrafine vs non-extrafine) randomized controlled studies are needed to evaluate whether changes in small-airway abnormalities correlate with improvement in clinical outcomes. Similarly, and even more importantly, clinical trials are needed to evaluate whether extrafine formulations would represent a specific therapeutic option for specific groups of patients ("clinical phenotypes") characterized by enhanced small airway dysfunctions [148]. In summary, a proper small airways diagnostic assessment in routine clinical 
practice with early recognition of small-airways dysfunction is essential for an optimal management of asthma, particularly for early-stage diseases, when subjects are often asymptomatic and routine pulmonary function tests may be within normal ranges, and enables the physician to start treatment targeting the bronchial tree from beginning to end [149-151].

\section{Competing interests}

The Authors declare that they have no competing interests.

\section{Authors' contributions}

Each author was responsible for the clinical work, collection and analysis of data and drafting the manuscript. All authors read and approved the final manuscript.

\section{Author details}

${ }^{1}$ Allergy and Pneumology Outpatient Clinic, Bergamo, Italy. ${ }^{2}$ Departmental Unit of Allergology, Immunology \& Pulmonary Diseases, Fondazione Poliambulanza, Via Bissolati, 57, Brescia 25124, Italy. ${ }^{3}$ Respiratory Unit, Mater Salutis Hospital, Legnago, Verona, Italy.

\section{Received: 7 July 2015 Accepted: 17 November 2015}

\section{Published online: 01 December 2015}

\section{References}

1. Pearce N, Ait-Khaled N, Beasley R, Mallol J, Keil U, Mitchell E, et al. Worldwide trends in the prevalence of asthma symptoms: phase III of the International Study of Asthma and Allergies in Childhood (ISAAC). Thorax. 2007:9:758-66.

2. World Health Organization Asthma fact sheet. Date last updated November 2013. www.who.int/mediacentre/factsheets/fs307/en/index.html.

3. Vos T, Barber R. M, Bell B. Global, regional, and national incidence, prevalence, and years lived with disability for 301 acute and chronic diseases and injuries in 188 countries, 1990-2013: a systematic analysis for the Global Burden of Disease Study 2013. Lancet 2015; Volume 386: No. 9995, 743-800.

4. The Global Asthma Report 2014 . http://www.globalasthmareport.org/.

5. The European Severe Asthma Survey,2005. http://www.efanet.org.

6. Lung Health in Europe-Facts and figures. Abbreviated version of the European Lung White Book. http://www.erswhitebook.org.

7. Accordini S, Corsico A, Cerveri I, Gislason D, Gulsvik A, Janson C, et al. The socio-economic burden of asthma is substantial in Europe. Allergy. 2008;63: $116-24$

8. Masoli M, Fabian D, Holt S, Beasley R. The global burden of asthma: executive summary of the GINA Dissemination Committee Report. Allergy. 2004;59:469-78.

9. GINA Report, Global Strategy for Asthma Management and Prevention: Global Initiative for Asthma; 2015. Available from: www.ginasthma.org.

10. National Asthma Education and Prevention Program: Expert Panel Report 3. Guidelines for the diagnosis and management of asthma. Bethesda: National Institutes of Health; 2007.

11. Bateman ED, Boushey HA, Bousquet J, Busse WW, Clark TJ, Pauwels RA et al. Can guideline-defined asthma control be achieved? The Gaining Optimal Asthma ControL study. Am

J Respir Crit Care Med. 2004;170:836-44.

12. Demoly P, Annunziata K, Gubba E, Adamek L. Repeated cross-sectional survey of patient-reported asthma control in Europe in the past 5 years. Eur Respir Rev. 2012;21:66-74.

13. Price D, Ali M, Burden A, Chisholm A, Lee AJ, Kemp L, et al. Effectiveness of combination therapies: real-world versus randomized controlled trials. Prim Care Respir J. 2010;19:A13.

14. Partridge MR, van der Molen T, Myrseth SE, Busse WW. Attitudes and actions of asthma patients on regular maintenance therapy: the INSPIRE study. BMC Pulm Med. 2006:6:13.

15. Haughney J, Price D, Kaplan A, Chrystyn H, Horne R, May N, et al. Achieving asthma control in practice: understanding the reasons for poor control. Respir Med. 2008;102:1681-93.
16. Caminati M, Bettoncelli G, Magnoni MS, Rizzi A, Testi R, Passalacqua G, et al. The level of control of mild asthma in general practice: an observational community-based study. J Asthma2014;51(1):91-6.

17. Chipps BE, Zeiger RS, Dorenbaum A, Borish L, Wenzel SE, Miller DP, et al. Assessment of asthma control and asthma exacerbations in the epidemiology and natural history of asthma: outcomes and treatment regimens (TENOR) observational cohort. Curr Respir Care Rep 2012;1:259-69.

18. Accordini S, Bugiani M, Arossa W, Gerzeli S, Marinoni A, Olivieri M, et al. Poor control increases the economic cost of asthma. A multicentre population-based study. Int Arch Allergy Immunol 2006;141:189-98.

19. Van Ganse E, Laforest L, Pietri G, Boissel JP, Gormand F, Ben-Joseph R, et al. Persistent asthma: disease control, resource utilisation and direct costs. Eur Respir I 2002;20:260-7.

20. Sims EJ, Price D, Haughney J, Ryan D, Thomas M. Current control and future risk in asthma management. Allergy Asthma Immunol Res. 2011;3:217-25.

21. Dima AL, Hernandez G, Cunillera O, Ferrer M, de Bruin M. ASTRO-LAB group. Asthma inhaler adherence determinants in adults: systematic review of observational data. Eur Respir J2015 Apr;45(4):994-1018.

22. Lavorini F, Usmani OS. Correct inhalation technique is critical in achieving good asthma control. Prim Care Respir J. 2013;22(4):383-92.

23. Brusselle G, Bracke K. Targeting immune pathways for therapy in asthma and chronic obstructive pulmonary disease. Ann Am Thorac Soc. 2014:11 Suppl 5:S322-8.

24. Boulet LP. Influence of comorbid conditions on asthma. Eur Respir J. 2009;33(4):897-906.

25. van der Wiel E, ten Hacken NH, Postma DS, van den Berge M. Small-airways dysfunction associates with respiratory symptoms and clinical features of asthma: a systematic review. J Allergy Clin Immunol. 2013;131:646-57.

26. Macklem PT, Mead J. Resistance of central and peripheral airways measured by a retrograde catheter. J Appl Physiol. 1967;22:395-401.

27. Hamid Q, Song Y, Kotsimbos TC, Minshall E, Bai TR, Hegele RG, Hogg JC, et al. Inflammation of small airways in asthma. J Allergy Clin Immunol. 1997;100(1):44-51.

28. Halwani R, Al-Muhsen S, Hamid Q. Airway remodeling in asthma. Curr Opin Pharmacol. 2010;10(3):236-45.

29. Jarjour NN, Erzurum SC, Bleecker ER, Calhoun WJ, Castro M, Comhair SA, et al. Severe asthma: lessons learned from the National Heart, Lung, and Blood Institute Severe Asthma Research Program. Am J Respir Crit Care Med. 2012;185(4):356-62

30. Mauad T, Bel EH, Sterk PJ. Asthma therapy and airway remodeling. J Allergy Clin Immunol. 2007:120(5):997-1009.

31. Mead J. The lung's "quiet zone". N Engl J Med. 1970;282:1318-9.

32. Verbanck S. Physiological measurement of the small airways. Respiration. 2012;84:177-88

33. Usmani OS. Small airways dysfunction in asthma: evaluation and management to improve asthma control. Allergy Asthma Immunol Res. 2014;6(5):376-88.

34. van den Berge M, ten Hacken NH, Cohen J, Douma WR, Postma DS. Small airway disease in asthma and COPD: clinical implications. Chest. 2011:139:412-23.

35. Contoli M, Bousquet J, Fabbri LM, Magnussen H, Rabe KF, Siafakas NM, et al. The small airways and distal lung compartment in asthma and COPD: a time for reappraisal. Allergy. 2010;65:141-51.

36. Anderson WJ, Zajda E, Lipworth BJ. Are we overlooking persistent small airways dysfunction in community-managed asthma? Ann Allergy Asthma Immunol. 2012;109:185-9.

37. Perez T, Chanez P, Dusser D, Devillier P. Small airway impairment in moderate to severe asthmatics without significant proximal airway obstruction. Respir Med. 2013;107(11):1667-74.

38. Scichilone N, Battaglia S, Olivieri D, Bellia V. The role of small airways in monitoring the response to asthma treatment: what is beyond FEV1? Allergy. 2009;64:1563-9.

39. Schiphof-Godart L, van der Wiel E, Ten Hacken NH, van den Berge M, Postma DS, van der Molen T, et al. Development of a tool to recognize small airways dysfunction in asthma (SADT). Health Qual Life Outcomes. 2014;12:155.

40. Kaminsky DA, Irvin CG, Gurka DA, Feldsien DC, Wagner EM, Liu MC, et al. Peripheral airways responsiveness to cool, dry air in normal and asthmatic individuals. Am J Respir Crit Care Med. 1995;152:1784-90.

41. Decramer M, Demedts M, van de Woestijne KP. Isocapnic hyperventilation with cold air in healthy non-smokers, smokers and asthmatic subjects. Bull Eur Phys Respir. 1984;20:237-43.

42. Fonseca-Guedes $\mathrm{CH}$, Cabral AL, Martins MA. Exercise-induced bronchospasm in children: comparison of FEV1 and FEF $25-75 \%$ responses. Pediatr Pulmonol. 2003:36:49-54. 
43. Aronsson D, Tufvesson E, Bjermer L. Comparison of central and peripheral airway involvement before and during methacholine, mannitol and eucapnic hyperventilation challenges in mild asthmatics. Clin Respir J. 2011;5:10-8.

44. Lee JH, Lee YW, Shin YS, Jung YH, Hong CS, Park JW, et al. Exercise-induced airway obstruction in young asthmatics measured by impulse oscillometry. J Investig Allergol Clin Immunol. 2010;20:575-81.

45. Gustafsson PM, Ljungberg HK, Kjellman B. Peripheral airway involvement in asthma assessed by single-breath SF6 and He washout. Eur Respir J. 2003;21:1033-9.

46. Ljungberg HK, Gustafsson PM. Peripheral airway function in childhood asthma, assessed by single-breath He and SF6 washout. Pediatr Pulmonol. 2003;36:339-47.

47. Chinellato I, Piazza M, Peroni D, Sandri M, Chiorazzo F, Boner AL, Piacentini G, et al. Bronchial and alveolar nitric oxide in exercise-induced bronchoconstriction in asthmatic children. Clin Exp Allergy. 2012;42(8):1190-6.

48. Linkosalo L, Lehtimäki L, Holm K, et al. Relation of bronchial and alveolar nitric oxide to exercise-induced bronchoconstriction in atopic children and adolescents. Pediatr Allergy Immunol. 2012;23(4):360-6.

49. Kraft M, Pak J, Martin RJ, et al. Distal lung dysfunction at night in nocturnal asthma. Am J Respir Crit Care Med. 2001;163:1551-6.

50. Kraft M, Djukanovic R, Wilson S, Holgate ST, Martin RJ. Alveolar tissue inflammation in asthma. Am J Respir Crit Care Med. 1996;154:1505-10.

51. Martin RJ, Cicutto LC, Smith HR, Ballard RD, Szefler SJ. Airways inflammation in nocturnal asthma. Am Rev Respir Dis. 1991;143(2):351-7.

52. Lehtimäki L Kankaanranta H, Saarelainen S, Turjanmaa V, Moilanen E. Increased alveolar nitric oxide concentration in asthmatic patients with nocturnal symptoms. Eur Respir J. 2002;20:841-5.

53. Dixon AE, Holguin F, Sood A, Salome CM, Pratley RE, Beuther DA, et al. American Thoracic Society Ad Hoc Subcommittee on Obesity and Lung Disease. An official American Thoracic Society Workshop report: obesity and asthma. Proc Am Thorac Soc. 2010;7:325-35.

54. Al-Alwan A, Bates JH, Chapman DG, Kaminsky DA, DeSarno MJ, Irvin CG et al. The nonallergic asthma of obesity. A matter of distal lung compliance. Am J Respir Crit Care Med. 2014;189(12):1494-502.

55. Takeda T, Oga T, Niimi A, Matsumoto H, Ito I, Yamaguchi M, et al. Relationship between Small Airway Function and Health Status, Dyspnea and Disease Control in Asthma. Respiration. 2010;80:120-6.

56. Pisi R, Tzani $P$, Aiello M, Martinelli E, Marangio E, Nicolini G, et al. Small airway dysfunction by impulse oscillometry in asthmatic patients with normal forced expiratory volume in the 1st second values. Allergy Asthma Proc. 2013;34(1):e14-20.

57. Manoharan A, Anderson WJ, Lipworth J, Ibrahim I, Lipworth BJ. Small airway dysfunction is associated with poorer asthma control. Eur Respir J. 2014;44(5):1353-5.

58. Lipworth B, Manoharan A, Anderson W. Unlocking the quiet zone: the small airway asthma phenotype. Lancet Respir Med. 2014;2:497-506.

59. Bacharier LB, Strunk RC, Mauger D, White D, Lemanske RF Jr, Sorkness CA, et al. Classifying asthma severity in children: mismatch between symptoms, medication use, and lung function. Am J Respir Crit Care Med. 2004;170(4):426-32.

60. Rao DR, Gaffin JM, Baxi SN, Sheehan WJ, Hoffman EB, Phipatanakul W, et al. The utility of forced expiratory flow between $25 \%$ and $75 \%$ of vital capacity in predicting childhood asthma morbidity and severity. J Asthma. 2012;49:586-92.

61. Shi Y, Aledia AS, Tatavoosian AV, Vijayalakshmi S, Galant SP, George SC, et al. Relating small airways to asthma control by using impulse oscillometry in children. J Allergy Clin Immunol. 2012;129:671-8.

62. Shi Y, Aledia AS, Galant SP, George SC. Peripheral airway impairment measured by oscillometry predicts loss of asthma control in children. J Allergy Clin Immunol. 2013;131:718-23.

63. Teague WG, Tustison NJ, Altes TA. Ventilation heterogeneity in asthma J Asthma. 2014;51(7):677-84.

64. McCarthy DS, Spencer R, Greene R, Milic-Emili J. Measurement of "closing volume" as a simple and sensitive test for early detection of small airway disease. Am J Med. 1972;52:747-51.

65. Crawford AB, Makowska M, Paiva M, Engel LA. Convection- and diffusion dependent ventilation maldistribution in normal subjects. J Appl Physiol. 1985;59:838-46.

66. Verbanck S, Paiva M. Model simulations of gas mixing and ventilation distribution in the human lung. J Appl Physiol. 1990;69:2269-79.

67. Bourdin A, Paganin F, Préfaut C, Kieseler D, Godard P, Chanez P, et al. Nitrogen washout slope in poorly controlled asthma. Allergy. 2006;61:85-9.
68. Singer F, Abbas C, Yammine S, Casaulta C, Frey U, Latzin P, et al. Abnormal small airways function in children with mild asthma. Chest. 2014;145(3):492-9.

69. Farah CS, King GG, Brown NJ, Downie SR, Kermode JA, Hardaker KM, et al. The role of the small airways in the clinical expression of asthma in adults. J Allergy Clin Immunol. 2012;129:381-7.

70. Farah CS, King GG, Brown NJ, Peters MJ, Berend N, Salome CM, et al. Ventilation heterogeneity predicts asthma control in adults following inhaled corticosteroid dose titration. J Allergy Clin Immunol. 2012;130:61-8.

71. Thompson BR, Douglass JA, Ellis MJ, Kelly VJ, O'Hehir RE, King GG, Verbanck S, et al. Peripheral lung function in patients with stable and unstable asthma. J Allergy Clin Immunol. 2013;131(5):1322-8.

72. Van Vyve T, Chanez P, Lacoste JY, Bousquet J, Michel FB, Godard P, et al. Comparison between bronchial and alveolar samples of bronchoalveolar lavage fluid in asthma. Chest. 1992;102:356-61.

73. Mahut B, Delacourt C, Zerah-Lancner F, De Blic J, Harf A, Delclaux C, et al. Increase in alveolar nitric oxide in the presence of symptoms in childhood asthma. Chest. 2004;125:1012-8.

74. Lehtimäki L, Kankaanranta H, Saarelainen S, Turjanmaa V, Moilanen E. Peripheral inflammation in patients with asthmatic symptoms but normal lung function. J Asthma. 2005;42:605-9.

75. Brindicci C, Ito K, Barnes PJ, Kharitonov SA. Differential flow analysis of exhaled nitric oxide in patients with asthma of differing severity. Chest. 2007;131:1353-62.

76. Paraskakis E, Brindicci C, Fleming L, Krol R, Kharitonov SA, Wilson NM, et al. Measurement of bronchial and alveolar nitric oxide production in normal children and children with asthma. Am J Respir Crit Care Med. 2006;174:260-7.

77. Corcuera-Elosegui P, Sardón-Prado O, Aldasoro-Ruiz A, Korta-Murua J, Mintegui-Aramburu J, Emparanza-Knorr Jl, et al. Inflammatory patterns in asthmatic children based on alveolar nitric oxide determination. Arch Bronconeumol. 2015;51(6):279-84.

78. Puckett JL, Taylor RW, Leu SY, Guijon OL, Aledia AS, Galant SP, et al. Clinical patterns in asthma based on proximal and distal airway nitric oxide categories. Respir Res. 2010;11:47.

79. Scichilone N, Battaglia S, Taormina S, Modica V, Pozzecco E, Bellia V, et al. Alveolar nitric oxide and asthma control in mild untreated asthma. J Allergy Clin Immunol. 2013;131:1513-7.

80. Bateman ED, Reddel HK, Eriksson G, Peterson S, Ostlund O, Sears MR, et al. Overall asthma control: the relationship between current control and future risk. J Allergy Clin Immunol. 2010;125:600-8.

81. Schatz M, Zeiger RS, Yang SJ, Chen W, Crawford W, Sajjan S, et al. The relationship of asthma impairment determined by psychometric tools to future asthma exacerbations. Chest. 2012;141:66-72.

82. Romagnoli M, Caramori G, Braccioni F, Ravenna F, Barreiro E, Siafakas NM et al. Near-fatal asthma phenotype in the ENFUMOSA cohort. Clin Exp Allergy. 2007;37(4):552-7.

83. GINA Report, Global Strategy for Asthma Management and Prevention: Global Initiative for Asthma; may 2014. Available from: www.ginasthma.org

84. in 't Veen JC, Beekman AJ, Bel EH. Recurrent exacerbations in severe asthma are associated with enhanced airway closure during stable episodes. Am J Respir Crit Care Med. 2000;161:1902-6.

85. Mahut B, Peiffer C, Bokov P, et al. Gas trapping is associated with severe exacerbation in asthmatic children. Respir Med. 2010;104:1230-3.

86. Niimi A, Matsumoto $H$, Amitani $R$, et al. Airway wall thickness in asthma assessed by computed tomography. Relation to clinical indices. Am J Respir Crit Care Med. 2000;162:1518-23.

87. McNulty W, Usmani OS. Techniques of assessing small airways dysfunction. Eur Clin Respir J. 2014.

88. Busacker A, Newell JD Jr, Keefe T, Hoffman EA, Granroth JC, Castro M, et al. A multivariate analysis of risk factors for the air-trapping asthmatic phenotype as measured by quantitative CT analysis. Chest. 2009;135:48-56.

89. Reddel HK, Taylor DR, Bateman ED, Boulet LP, Boushey HA, Busse WW, et al. An official American Thoracic Society/European Respiratory Society statement: asthma control and exacerbations: standardizing endpoints for clinical asthma trials and clinical practice. Am J Respir Crit Care Med. 2009;180(1):59-99.

90. Wagner EM, Liu MC, Weinmann GG, Permutt S, Bleecker ER. Peripheral lung resistance in normal and asthmatic subjects. Am Rev Respir Dis. 1990;141(3):584-8.

91. Segal LN, Goldring RM, Oppenheimer BW. Disparity between proximal and distal airway reactivity during methacholine challenge. COPD. 2011.;8(3): $145-52$.

92. Boudewijn IM, Telenga ED, van der Wiel E, van der Molen $T$, Schiphof $L$, Ten Hacken $\mathrm{NH}$, et al. Less small airway dysfunction in asymptomatic bronchial hyperresponsiveness than in asthma. Allergy. 2013;68(11):1419-26. 
93. Beretta E, Tana F, Grasso GS, Bartesaghi M, Novelli L, Pesci A, et al. Regional differences in bronchial reactivity assessed by respiratory impedance. Respir Physiol Neurobiol. 2014;192:23-9.

94. Telenga $\mathrm{ED}$, van den Berge $\mathrm{M}$, Ten Hacken $\mathrm{NH}$, Riemersma RA, van der Molen T, Postma DS, et al. Small airways in asthma:their independent contribution to the severity of hyperresponsiveness. Eur Respir J. 2013;41(3):752-4.

95. Downie S, Salome C, Verbanck S. Ventilation heterogeneity is a major determinant of airway hyperresponsiveness in asthma, independent of airway inflammation. Thorax. 2007:62:684-9.

96. Gibbons WJ, Sharma A, Macklem PT. Detection of excessive bronchoconstriction in asthma. 1996. Am J Respir Crit Care Med. 1996:153:582-9.

97. Lee $\mathrm{P}$, Abisheganaden J, Chee CB, Wang YT. A new asthma severity index: a predictor of near-fatal asthma? Eur Respir J. 2001;18:272-8.

98. Abisheganaden J, Chan CC, Chee CB, Wang YT. Methacholine-induced fall in FV as a marker of asthma severity. Respir Med. 1999;93:277-82.

99. Yoo Y, Choung JT, Yu J, Kim do K, Choi SH, Koh YY, et al. Comparison of percentage fall in FVC at the provocative concentration of methacholine causing a $20 \%$ fall in FEV1 between patients with asymptomatic bronchial hyperresponsiveness and mild asthma. Chest. 2007:132:106-11.

100. Alfieri V, Aiello M, Pisi R, Tzani P, Mariani E, Marangio E, et al. Small airway dysfunction is associated to excessive bronchoconstriction in asthmatic patients. Respir Res. 2014;15(1):86.

101. Laube $B L$, Janssens HM, de Jongh FH, Devadason SG, Dhand R, Diot $P$, et al. European Respiratory Society; International Society for Aerosols in Medicine. What the pulmonary specialist should know about the new inhalation therapies. Eur Respir J. 2011;37(6):1308-31.

102. Leach CL. Improved delivery of inhaled steroids to the large and small airways. Respir Med. 1998;92(suppl A):3-8.

103. Leach CL, Davidson PJ, Hasselquist BE, Boudreau RJ. Lung deposition of hydrofluoroalkane-134a beclomethasone is greater than that of chlorofluorocarbon fluticasone and chlorofluorocarbon beclomethasone: a cross-over study in healthy volunteers. Chest. 2002;122:510-6.

104. Carvalho TC, Peters Jl, Williams RO. Influence of particle size on regional lung deposition—what evidence is there? Int J Pharm. 2011;406:1-10.

105. Verbanck S, Schuermans D, Paiva M, Vincken W. The functional benefit of anti-inflammatory aerosols in the lung periphery. J Allergy Clin Immunol. 2006;118(2):340-6.

106. Hoshino M. Comparison of effectiveness in ciclesonide and fluticasone propionate on small airway function in mild asthma. Allergol Int. 2010;59(1):59-66

107. Micheletto C, Guerriero M, Tognella S, Dal Negro RW. Effects of HFA- and CFC-beclomethasone dipropionate on the bronchial response to methacholine (MCh) in mild asthma. Respir Med. 2005;99:850-5.

108. Nicolini G, Chetta A, Simonazzi A. Both bronchial and alveolar exhaled nitric oxide are reduced with extrafine beclomethasone dipropionate in asthma. Allergy Asthma Proc. 2010;31(5):85-90.

109. Hauber H, Taha R, Bergeron C, Migounov V, Hamid Q, Olivenstein R, et al. Effects of hydrofluoroalkane and dry powder-formulated corticosteroids on sputum inflammatory markers in asthmatic patients. Can Respir J. 2006; 13(2):73-8.

110. Goldin JG, Tashkin DP, Kleerup EC, Greaser LE, Haywood UM, Sayre JW, et al. Comparative effects of hydrofluoroalkane and chlorofluorocarbon beclomethasone dipropionate inhalation on small airways: assessment with functional helical thin section computed tomography. J Allergy Clin Immunol. 1999;104:S258-67.

111. Barnes N, Price D, Colice G, Chisholm A, Dorinsky P, Hillyer EV, et al. Asthma control with extrafine-particle hydrofluoroalkane-beclometasone vs. large particle chlorofluorocarbon-beclometasone: a real-world observational study. Clin Exp Allergy. 2011:41(11):1521-32.

112. Colice G, Martin RJ, Israel E, Roche N, Barnes N, Burden A, et al. Asthma outcomes and costs of therapy with extrafine beclomethasone and fluticasone. J Allergy Clin Immunol. 2013;132(1):45-54.

113. Price D, Thomas M, Haughney J, Lewis RA, Burden A, von Ziegenweidt J, et al. Real-life comparison of beclometasone dipropionate as an extrafineor larger-particle formulation for asthma. Respir Med. 2013;107(7):987-1000

114. Boulet $L P$, Bateman ED, Voves R, Müller T, Wolf S, Engelstätter $R$, et al. A randomized study comparing ciclesonide and fluticasone propionate in patients with moderate persistent asthma. Respir Med. 2007;101:1677-86.
115. Ohbayashi H, Adachi M. Hydrofluoroalkane-beclomethasone dipropionate effectively improves airway eosinophilic inflammation including the distal airways of patients with mild to moderate persistent asthma as compared with fluticasone propionate in a randomized open double-cross study. Allergol Int. 2008;57:231-9.

116. Martin RJ, Price D, Roche N, Israel E, van Aalderen WM, Grigg J, et al. Costeffectiveness of initiating extrafine- or standard size-particle inhaled corticosteroid for asthma in two health-care systems: a retrospective matched cohort study. PJ Prim Care Respir Med. 2014;24:14081.

117. Pedersen S, Engelstätter R, Weber HJ. Efficacy and safety of ciclesonide once daily and fluticasone propionate twice daily in children with asthma. Pulm Pharmacol Ther. 2009;22(3):214-20.

118. Scichilone N, Benfante A, Morandi L, Bellini F, Papi A.. Impact of extrafine formulations of inhaled corticosteroids/long-acting beta-2 agonist combinations on patient-related outcomes in asthma and COPD. Patient Relat Outcome Meas. 2014;5:153-62

119. Fabbri LM, Nicolini G, Olivieri D, Papi A. Inhaled beclometasone dipropionate/ formoterol extra-fine fixed combination in the treatment of asthma: evidence and future perspectives. Expert Opin Pharmacother. 2008;9(3):479-90.

120. De Backer W, Devolder A, Poli G, Acerbi D, Monno R, Herpich C, et al. Lung deposition of BDP/formoterol HFA pMDI in healthy volunteers, asthmatic, and COPD patients. J Aerosol Med Pulm Drug Deliv. 2010;23(3):137-48.

121. Papi A, Paggiaro P, Nicolini G, Vignola AM, Fabbri LM; ICAT SE study group. Beclomethasone/formoterol vs fluticasone/salmeterol inhaled combination in moderate to severe asthma. Allergy. 2007;62(10):1182-8.

122. Popov TA, Petrova D, Kralimarkova TZ, Ivanov Y, Popova T, Peneva M, et al. Real life clinical study design supporting the effectiveness of extra-fine inhaled beclomethasone/formoterol at the level of small airways of asthmatics. Pulm Pharmacol Ther. 2013;26(6):624-9

123. Corda L, Gardenghi GG, Modina D, Montemurro LT, Novali M, Tantucci C, et al. Effects on small airway obstruction of long-term treatments with beclomethasone/formoterol hydrofluoroalkane (metered-dose inhaler) versus fluticasone/salmeterol (dry-powder inhaler) in asthma: a preliminary study. Allergy Asthma Proc. 2011;32(6):29-34

124. Scichilone N, Battaglia S, Sorino C, Paglino G, Martino L, Paternò A, et al. Effects of extra-fine inhaled beclomethasone/formoterol on both large and small airways in asthma. Allergy. 2010;65(7):897-902.

125. Bulac S, Cimrin A, Ellidokuz H. The effect of beclometasone Dipropionate/ Formoterol extra-fine fixed combination on the peripheral airway inflammation in controlled asthma. J Aerosol Med Pulm Drug Deliv. 2015;28(2):82-7.

126. Kirsten AM, Watz $H$, Brindicci $C$, Piccinno A, Magnussen $H$. Effects of beclomethason/formoterol and budesonide/formoterol fixed combinations on lung function and airway inflammation in patients with mild to moderate asthma. Pulm Pharmacol Ther. 2015;31:79-84

127. Vos W, De Backer J, Poli G, De Volder A, Ghys L, Van Holsbeke C, et al. Novel functional imaging of changes in small airways of patients treated with extrafine beclomethasone/formoterol. Respiration. 2013;86(5):393-401.

128. Huchon G, Magnussen H, Chuchalin A, Dymek L, Gonod FB, Bousquet J, et al. Lung function and asthma control with beclomethasone and formoterol in a single inhaler. Respir Med. 2009;103:41-9.

129. Müller V, Gálffy G, Eszes N, Losonczy G, Bizzi A, Nicolini G, et al. Asthma control in patients receiving inhaled corticosteroid and long-acting beta2-agonist fixed combinations. A real-life study comparing dry powder inhalers and a pressurized metered dose inhaler extrafine formulation. BMC Pulm Med. 2011;11:40

130. Allegra L, Cremonesi G, Girbino G, Ingrassia E, Marsico S, Nicolini G, Terzano C; PRISMA (PRospectlve Study on asthMA control) Study Group. Real-life prospective study on asthma control in Italy: cross-sectional phase results. Respir Med. 2012;106:205-14.

131. Terzano C, Cremonesi G, Girbino G, Ingrassia E, Marsico S, Nicolini G, Allegra L; PRISMA (PRospectlve Study on asthMA control) Study Group. 1-year prospective real life monitoring of asthma control and quality of life in Italy. Respir Res. 2012;13:112

132. Price D, Small I, Haughney J, Ryan D, Gruffydd-Jones K, Lavorini F, et al. Clinical and cost effectiveness of switching asthma patients from fluticasone-salmeterol to extra-fine particle beclometasone-formoterol: a retrospective matched observational study of real-world patients. Prim Care Respir J. 2013;22(4):439-48

133. Gerzeli S, Rognoni C, Quaglini S, Cavallo MC, Cremonesi G, Papi A, et al. Cost-effectiveness and cost-utility of beclomethasone/formoterol versus fluticasone propionate/salmeterol in patients with moderate to severe asthma. Clin Drug Investig. 2012;32(4):253-65. 
134. Brusselle G, Peché R, Van den Brande P, Verhulst A, Hollanders W, Bruhwyler J, et al. Real-life effectiveness of extrafine beclometasone dipropionate/ formoterol in adults with persistent asthma according to smoking status. Respir Med. 2012:106(6):811-9.

135. Price D, Bjermer L, Popov TA, Chisholm A. Integrating evidence for managing asthma in patients who smoke. Allergy Asthma Immunol Res. 2014;6(2):114-20.

136. Singh RK, Tandon R, Dastidar SG, Ray A. A review on leukotrienes and their receptors with reference to asthma. J Asthma. 2013;50(9):922-31.

137. Tufvesson E, Nihlberg K, Westergren-Thorsson G, Bjermer L. Leukotriene receptors are differently expressed in fibroblast from peripheral versus central airways in asthmatics and healthy controls. Prostaglandins Leukot Essent Fatty Acids. 2011:85:67-73.

138. Nakaji H, Petrova G, Matsumoto H, Iwata T, Ito I, Oguma T, et al. Effects of 24-week add-on treatment with ciclesonide and montelukast on small airways inflammation in asthma. Ann Allergy Asthma Immunol. 2013;110(3):198-203.

139. Nieto A, Pamies R, Oliver F, Medina A, Caballero L, Mazon A, et al. Montelukast improves pulmonary function measured by impulse oscillometry in children with asthma (Mio study). Respir Med. 2006;100(7): 1180-5.

140. Gao JM, Cai F, Peng M, Ma Y, Wang B. Montelukast improves air trapping, not airway remodeling, in patients with moderate-to-severe asthma: a pilot study. Chin Med J (Engl). 2013;126(12):2229-34.

141. Zeidler MR, Kleerup EC, Goldin JG, Kim HJ, Truong DA, Simmons MD, et al. Montelukast improves regional air-trapping due to small airways obstruction in asthma. Eur Respir J. 2006:27(2):307-15.

142. Kraft M, Cairns CB, Ellison MC, Pak J, Irvin C, Wenzel S, et al. Improvements in distal lung function correlate with asthma symptoms after treatment with oral montelukast. Chest. 2006;130:1726-32.

143. Spahn JD, Covar RA, Jain N, Gleason M, Shimamoto R, Szefler SJ, et al. Effect of montelukast on peripheral airflow obstruction in children with asthma. Ann Allergy Asthma Immunol. 2006:96:541-9.

144. Fritscher LG, Rodrigues MT, Zamel N, Chapman KR. The effect of montelukast on exhaled nitric oxide of alveolar and bronchial origin in inhaled corticosteroid-treated asthma. Respir Med. 2009;103(2):296-300.

145. Tajiri T, Niimi A, Matsumoto H, Ito I, Oguma T, Otsuka K, et al. Comprehensive efficacy of omalizumab for severe refractory asthma: a timeseries observational study. Ann Allergy Asthma Immunol. 2014;113(4):470-5.

146. Pasha MA, Jourd'heuil D, Jourd'heuil F, Mahon L, Romero F, Feustel PJ, et al. The effect of omalizumab on small airway inflammation as measured by exhaled nitric oxide in moderate-to-severe asthmatic patients. Allergy Asthma Proc. 2014;35(3):241-9.

147. Ivancsó I, Böcskei R, Müller V, Tamási L. Extrafine inhaled corticosteroid therapy in the control of asthma. J Asthma Allergy. 2013;6:69-80.

148. Contoli M, Kraft M, Hamid Q, Bousquet J, Rabe KF, Fabbri LM, et al. Do small airway abnormalities characterize asthma phenotypes? In search of proof. Clin Exp Allergy. 2012:42(8):1150-60.

149. van den Berge $M$, ten Hacken $\mathrm{NH}$, van der Wiel E, Postma DS. Treatment of: targeting small airway inflammation in asthma. Allergy. 2013;68(1):16-26.

150. Bonini M, Usmani OS. The role of the small airways in the pathophysiology of asthma and chronic obstructive pulmonary disease. Ther Adv Respir Dis. 2015. [Epub ahead of print].

151. Usmani OS. Small-airway disease in asthma: pharmacological considerations. Curr Opin Pulm Med. 2015;21(1):55-67. doi:10.1097/MCP.0000000000000115.

\section{Submit your next manuscript to BioMed Central and we will help you at every step:}

- We accept pre-submission inquiries

- Our selector tool helps you to find the most relevant journal

- We provide round the clock customer support

- Convenient online submission

- Thorough peer review

- Inclusion in PubMed and all major indexing services

- Maximum visibility for your research

Submit your manuscript at www biomedcentral com/submit 